\title{
Antioxidant Properties and Cytotoxicity of White Mugwort (Artemisia lactiflora) Leaf Extract in Human Hepatocellular Carcinoma Cell Line $^{\dagger}$
}

\author{
Kanokwan KULPRACHAKARN ${ }^{1}$, Kanjana PANGJIT ${ }^{2}$, \\ Narisara PARADEE ${ }^{3}$, Somdet SRICHAIRATANAKOOL ${ }^{3}$, \\ Kittipan RERKASEM ${ }^{1,4}$ and Sakaewan OUNJAIJEAN ${ }^{1, *}$
}

\author{
${ }^{I} N C D$ Center of Excellence, Research Institute for Health Sciences, Chiang Mai University, \\ Chiang Mai 50200, Thailand \\ ${ }^{2}$ College of Medicine and Public Health, Ubon Ratchathani University, \\ Ubon Ratchathani 34190, Thailand \\ ${ }^{3}$ Department of Biochemistry, Faculty of Medicine, Chiang Mai University, Chiang Mai 50200, Thailand \\ ${ }^{4}$ Department of Surgery, Faculty of Medicine, Chiang Mai University, Chiang Mai 50200, Thailand
}

('Corresponding author's e-mail: sakaewan@gmail.com)

Received: 30 March 2018, Revised: 24 July 2018, Accepted: 26 August 2018

\begin{abstract}
The present study aims to investigate the antioxidant activity and cytotoxicity of white mugwort (Artemisia lactiflora) leaf extract in the human liver cancer cell line (HepG2 cell). Dried leaves of white mugwort were macerated in $80 \%(v / v)$ aqueous ethanol to get white mugwort leaf extract (WMLE). Spectrophotometrically methods were conducted to quantify the total phenolic content and the antioxidant capacity of the extract, and were found to be $213.33 \pm 17.80 \mathrm{mg}$ gallic acid equivalent and $27.20 \pm 1.06 \mathrm{mg}$ trolox equivalent per gram of dry extract, respectively. Cytotoxic effects of white WMLE on cell viability and cellular antioxidant defense against reactive oxygen species (ROS) were also examined. The WMLE showed weak ability to inhibit cell growth, with a $50 \%$ inhibitory concentration $\left(\mathrm{IC}_{50}\right)$ value of $148 \mu \mathrm{g} / \mathrm{mL}$. Furthermore, the extract exhibited antioxidant activity in HepG2 cells via the ability to lower cellular ROS in a dose-dependent fashion. The preliminary results of this investigation supported that WMLE exhibits strong antioxidant activities while remain considerably non-cytotoxic effect. However, more intensive studies are required to clarify the use of WMLE as a novel alternative medicine for the treatment of liver cancer.
\end{abstract}

Keywords: Antioxidant, cytotoxicity, white mugwort, reactive oxygen species, liver cancer

\section{Introduction}

Medicinal plants have been used for Ayurveda aspects for thousands of years [1]. World Health Organization (WHO) estimated that, majority of the world's population still relies mainly on traditional remedies. Herbs are benefit for health preservation in several dimensions such as better cultural acceptability, better body compatibility and less severe side effects [2]. With growing knowledge on the role of free radicals in human diseases, antioxidants have come into focus since their ability to inhibit free radical reactions, thus help protecting against free radical-induced oxidative damages [3].

\footnotetext{
${ }^{\dagger}$ Presented at the International Conference on Biomedical Sciences 2018: March 22 ${ }^{\text {nd }}-23^{\text {rd }}, 2018$
} 
http://wjst.wu.ac.th

Artemisia lactiflora Wall. ex DC (Asteraceae) is a species of flowering plant in the daisy family, native to Guizhou in China [4]. A. lactiflora is also known as white mugwort or 'jingjuchai' in Thailand. The leaves and flowering stems are used as internally drug formula in traditional Chinese medicine to treat menstrual and liver disorders [5]. In Thailand, white mugwort leaves are used for cooking and food dressing. White mugwort has many medicinal properties, including anticancer and anti-oxidative properties, as well as help control of blood circulation, dysmenorrhea, chronic hepatitis, cirrhosis, and vaginal discharge [6].

Major chemical constituents were isolated during alcoholic extraction of white mugwort including 7-hydroxycoumarin, 7-methoxycoumarin, aurantiamide, aurantiamide acetate, balanophonin, caffeic acid ethyl ester, methyl 3, 4-di-O-caffeoyl quinate, quercetin, methyl 3, 5-di-O-caffeoyl quinate, iso-vitexin, rutin, and kaempferol-3-O-beta-D-rutinoside [7]. Numbers of evidence have also been reported that white mugwort leaves contain beta-carotene, riboflavin, ascorbic acid, iron, protein, and calcium. Leaves contain lactone, bitter absinthin and anabsinthin, at about 3.6\% dry weight basis, which activate digestion and antimalarial effects. Monoterpene (narcotic thujone) and cytotoxic diacetylenic spiroketal enol ether, another constituent in white mugwort leave have been shown its anticancer effects, and are included in the treatment of menstrual and liver diseases. Furthermore, diacetylenic spiroketal enol ether epoxide, also called AL-1, has been discovered to inhibit tetradecanoylphorbol acetate (TPA)-induced tumor progression by reducing oxidative damage to the rat skin [8-10].

However, it has been observed that, till date, rare studies have focused on the relationship between white mugwort extract and human hepatocellular carcinoma cell lines, HepG2 cells, which are frequently used as in vitro alternatives to primary human hepatocytes [11]. Therefore, this study was designed to examine the antioxidant activities and cytotoxicity of the extract of white mugwort leaves in HepG2 cells.

\section{Materials and methods}

Chemicals and reagents

2',7'-dichlorodihydrofluorescein diacetate (DCFH-DA), 2,2'-azino-bis(3-ethylbenzothiazoline-6sulfonic acid) (ABTS), 6-hydroxy-2,5,7,8-tetramethylchroman-2-carboxylic acid (Trolox), and gallic acid were bought from Sigma-Aldrich, St. Louis, MO, USA. Folin-Ciocalteu's phenol reagent (Merck KGaA, Darmstadt, Germany), dimethyl sulfoxide (DMSO) (Fisher Scientific, UK), 3-(4,5-dimethylthiazol-2-yl)2,5-diphenyltetrazolium bromide (MTT), fetal bovine serum, hydrogen peroxide (35 \%), Dulbecco's modified Eagle's medium (DMEM), penicillin-streptomycin, and $0.5 \%$ trypsin-EDTA solution were purchased from GIBCO $^{\circledR}$ Invitrogen, CA, USA.

\section{Plant materials and preparation of plant extract}

White mugwort leaves were obtained from Baanpakkhuntum, Chiang Mai, Thailand. Leaves were dried successively in an electric oven for $24 \mathrm{~h}$ at $60{ }^{\circ} \mathrm{C}$. The dried powder of the white mugwort leaves $(100 \mathrm{~g})$ was soaked in $1,000 \mathrm{~mL}$ of $80 \%(\mathrm{v} / \mathrm{v})$ aqueous ethanol, overnight at room temperature. After that, the ethanol extract was filtered and the filtrate was evaporated using a rotary evaporator (yield $=38.12$ $\%$ ). The dried residue was kept at $-20^{\circ} \mathrm{C}$ until being used for further analysis.

\section{Analysis of total phenolic content}

The quantification of total phenolic content in the white mugwort leaf extract (WMLE) was measured by using the Folin-Ciocalteu method [12]. Briefly, WMLE was incubated in the dark with $10 \%$ Folin - Ciocalteu's phenol reagent for $3 \mathrm{~min}$. Then, the mixture was added with $7.5 \%$ sodium carbonate and stand in the dark for further $30 \mathrm{~min}$. Then, the optical density (OD) was read at $765 \mathrm{~nm}$ using a UV/Visible spectrophotometer. Gallic acid was used as the reference standard for the quantification of the total phenolic content and the results were showed as mg gallic acid equivalent (GAE)/g dry extract.

\section{Total antioxidant capacity assay}

The ABTS radical cation decolorization method [13] was adopted to determine the total radical scavenging activity of WMLE. Briefly, a stock $\mathrm{ABTS}^{\mathrm{o}^{+}}$solution was produced by mixing of $4.9 \mathrm{mM}$ 
http://wjst.wu.ac.th

potassium persulfate to $14 \mathrm{mM}$ of 2,2 azobis (2-amidinopropane) dihydrochloride, the mixture was incubated in the dark, at room temperature for $12 \mathrm{~h}$. The working $\mathrm{ABTS}^{\mathrm{O}^{+}}$was prepared by dilution of stock solution with distilled water till OD of the solution reached $0.70 \pm 0.02$ at $734 \mathrm{~nm}$. To determine antioxidant capacity, WMLE solution was added at a ratio 1:100 (v/v) to $\mathrm{ABTS}^{\circ+}$ working solution, then incubated for exactly $6 \mathrm{~min}$ in the dark at room temperature. The decrease in absorbance was measured at $734 \mathrm{~nm}$. Trolox (water - soluble vitamin E analogue) was used as the standard and results are expressed as mg Trolox equivalent antioxidant capacity (TEAC)/g of dry extract.

\section{Cell culture}

Human hepatocellular carcinoma (HepG2) cell line have been widely used to study biochemical and cytotoxic effects of a variety of chemicals and drugs [14]. HepG2 cells were cultured in complete DMEM medium supplemented with $100 \mathrm{IU} / \mathrm{mL}$ penicillin/streptomycin and $10 \%(v / v)$ of FBS in T-75 tissue culture flask, and incubated in humidified atmosphere at $37{ }^{\circ} \mathrm{C}, 5 \% \mathrm{CO}_{2}$ [15]. After reached $70 \%$ confluence, cells were harvested. $5 \times 10^{3}$ cells were plated in each well of 96-well plate and incubated overnight to allow attachment to the culture wells. After then, the medium was discarded and the test solution, which was diluted with the medium to a final concentration of $25-200 \mu \mathrm{g} / \mathrm{mL}$, was added to the well and incubated for further 24 or $48 \mathrm{~h}$. As basal control, the cells were cultured in the medium without test solution. All analysis was done in triplicate.

\section{Cell viability assay}

To investigate the effect of WMLE on cell viability, the MTT assay was performed according to the method described previously [16]. Briefly, the cells were incubated with MTT dye solution at $37{ }^{\circ} \mathrm{C}$ for 4 $\mathrm{h}$. At the end of time, the supernatant was removed and the purple formazan product formed was solubilized with DMSO into a colored solution. The optical density of solution was then read at 540/630 $\mathrm{nm}$ using a UV/Visible spectrophotometer. The results were recorded, percentage of inhibition were calculated, and the cytotoxicity of the extract was expressed as $\mathrm{IC}_{50}$ values; the concentration of sample which inhibits $50 \%$ of cell growth.

\section{Assessment of intracellular reactive oxygen species (ROS)}

Intracellular production of ROS was estimated using the oxidation-sensitive fluorescent probe; 2', 7'dichlorodihydrofluorescein diacetate (DCFH-DA) [17]. Briefly, HepG2 cells were treated with a different concentration of WMLE, ranging from 0.312 to $20 \mu \mathrm{g} / \mathrm{mL}$, at $37{ }^{\circ} \mathrm{C}$ for $24 \mathrm{~h}$. Then, the treated cells were washed 3 times with sterile PBS and labeled with $10 \mu \mathrm{M}$ DCFH-DA solution in the dark at $37^{\circ} \mathrm{C}$ for 30 min. Washing step was continue and the cells were challenged with $125 \mu \mathrm{M}$ hydrogen peroxide solution for $20 \mathrm{~min}$ in the dark. Immediately after time, the induction of cellular ROS production was examined using spectrofluorometer at excitation/emission wavelengths of 485/530 nm [18]. The fluorescence intensity (FI) value, directly proportional to the quantity of intracellular ROS, and is responsible for the level of cellular oxidative stress [19].

\section{Statistical analysis}

The results are reported as mean \pm standard error of mean (SEM) from triplicated, 3 independence analysis. Statistical analysis was carried out using GraphPad Prism version 7.00 for Windows, GraphPad Software, La Jolla California USA. Statistical significance was defined using one-way analysis of variance (ANOVA). $P<0.05$ was considered as a statistically significant difference.

\section{Results and discussions}

Analysis of the total phenolic content and antioxidant activity in WMLE

Folin - Ciocalteu method, commonly used method for the determination of phenolic quantity in various plant extracts was selected to determine the total phenolic content of WMLE. The result from triplicate, 3 independent experiments was found to be $213.33 \pm 17.80 \mathrm{mg}$ gallic acid equivalent (GAE)/g 
http://wjst.wu.ac.th

of dry extract (Table 1). Pi-Yu Chao and colleagues suggested that morin and quercetin may serve as principal flavonol constituents in the leaves of white mugwort [20].

Furthermore, total antioxidant capacity of WMLE was determined by modified Trolox equivalent total antioxidant capacity (TEAC) assay using its ability to decolorized $\mathrm{ABTS}^{\mathrm{o}^{+}}$cation. As evident from Table 1, the level of antioxidant capacity of WMLE was approximately $27.20 \pm 1.06 \mathrm{mg} \mathrm{TEAC} / \mathrm{g}$ of dry extract. Combined with the aforementioned results, it may be concluded that the presence of abundant phenolic compounds in WMLE contributed to its strong antioxidant potential. Indeed, phenolic compounds are composed of one or more aromatic rings which possessing hydroxyl groups, thus capable of inhibiting oxidoreduction by forming resonance-stabilized phenoxyl radicals [21]. In addition, quercetin, one of the most important bioflavonoids which is widely known for its antioxidant properties, play a vital roles in exhibiting beneficial health effects. Present of quercetin along with other flavonoids in white mugwort extract encourage the use of this plant as a source of potential antioxidants [22].

Table 1 The content of total phenolic and antioxidant activity of WMLE.

\begin{tabular}{lcc}
\hline \multicolumn{1}{c}{ Extract } & $\begin{array}{c}\text { Total phenolic content } \\
\text { (mg GAE/g of dry extract) }\end{array}$ & $\begin{array}{c}\text { Antioxidant activity } \\
\text { (mg TEAC/g of dry extract) }\end{array}$ \\
\hline White mugwort leaf extract & $213.33 \pm 17.80$ & $27.20 \pm 1.06$ \\
\hline $\begin{array}{l}\text { WMLE: white mugwort leaf extract; GAE: gallic acid equivalent; TEAC: Trolox equivalent antioxidant } \\
\text { capacity. Values are presented as mean } \pm \text { SEM }(\mathrm{n}=3) .\end{array}$
\end{tabular}

\section{Cytotoxicity study in HepG2 cells}

The cytotoxicity was determined using the MTT method based on the abatement of the soluble tetrazolium salt by mitochondrial dehydrogenase activity into a purple formazan product which could be simply determined by a spectrophotometer. The $50 \%$ inhibitory concentration $\left(\mathrm{IC}_{50}\right)$ value, refers to concentration of the plant extract which could inhibit $50 \%$ of cell growth. Such value obtained from the viability graph was simply defined as a parameter for cytotoxicity. In order to determine the $\mathrm{IC}_{50}$ values of the crude extract in the HepG2 cells, concentration-dependent assays were carried out at the concentration ranging from $25 \mu \mathrm{g} / \mathrm{mL}$ to $200 \mu \mathrm{g} / \mathrm{mL}$ for 24 and $48 \mathrm{~h}$, respectively. As shown in Figure 1 and Table 2, the extract decreased cell viability in a dose-dependent fashion and the $\mathrm{IC}_{50}$ value of WMLE was found to be $148 \mu \mathrm{g} / \mathrm{mL}$ after $24 \mathrm{~h}$ of incubation. Apparently, for $48 \mathrm{~h}$ incubation, WMLE decreased the amount of viable HepG2 cells in a concentration-dependent manner with $\mathrm{IC}_{50}$ value of $110 \mu \mathrm{g} / \mathrm{mL}$ (Figure 2 and Table 2). Recently, a novel polyacetylene, artemisidiyne A, was isolated from Artemisia lactiflora. This compound exhibited cytotoxicity against HCT-8, A549, and BCG-823 tumor cell lines with $\mathrm{IC}_{50}$ values of $7.5 \mu \mathrm{M}, 4.6 \mu \mathrm{M}$, and $1.1 \mu \mathrm{M}$, respectively [8].

Table 2 Cytotoxicity of WMLE at various concentrations in HepG2 cells for 24 and $48 \mathrm{~h}$.

\begin{tabular}{ccc}
\hline Concentration of WMLE $(\boldsymbol{\mu g} / \mathbf{m L})$ & \% Cell viability (24 h) & \% Cell viability (48 h) \\
\hline 0 & $100 \pm 0.00$ & $100 \pm 0.00$ \\
25 & $84 \pm 4.92^{*}$ & $82 \pm 1.24^{*}$ \\
50 & $81 \pm 2.28^{*}$ & $67 \pm 2.11^{*}$ \\
100 & $72 \pm 4.46^{*}$ & $52 \pm 1.14^{*}$ \\
200 & $24 \pm 3.78^{*}$ & $19 \pm 0.79^{*}$ \\
\hline
\end{tabular}

WMLE: white mugwort leaf extract. Values are expressed as mean \pm SEM $(\mathrm{n}=3) .{ }^{*} P<0.05$ compared to non-treatment control. 


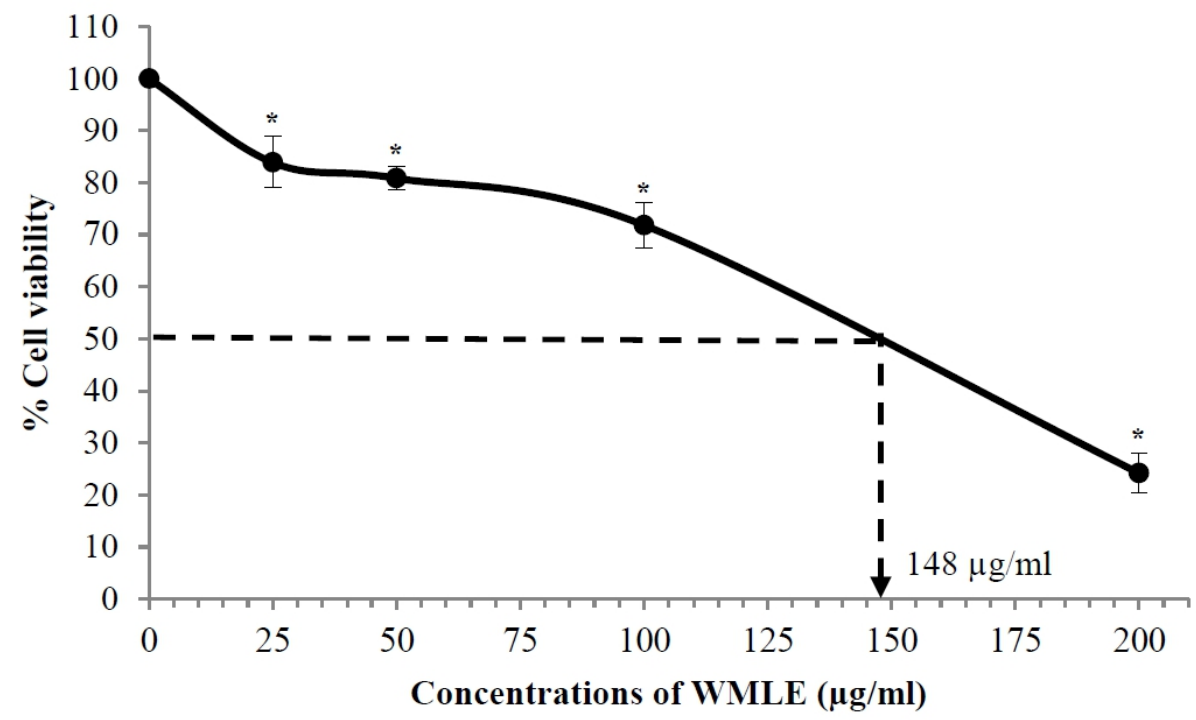

Figure 1 The percentage of cell viability of HepG2 cells against a various concentrations of WMLE (0 $200 \mu \mathrm{g} / \mathrm{mL}$ ) for $24 \mathrm{~h}$ of incubation. The data were obtained from 3 -independent triplicate experiments and are shown as mean \pm SEM. $* P<0.05$ compared to non-treatment control.

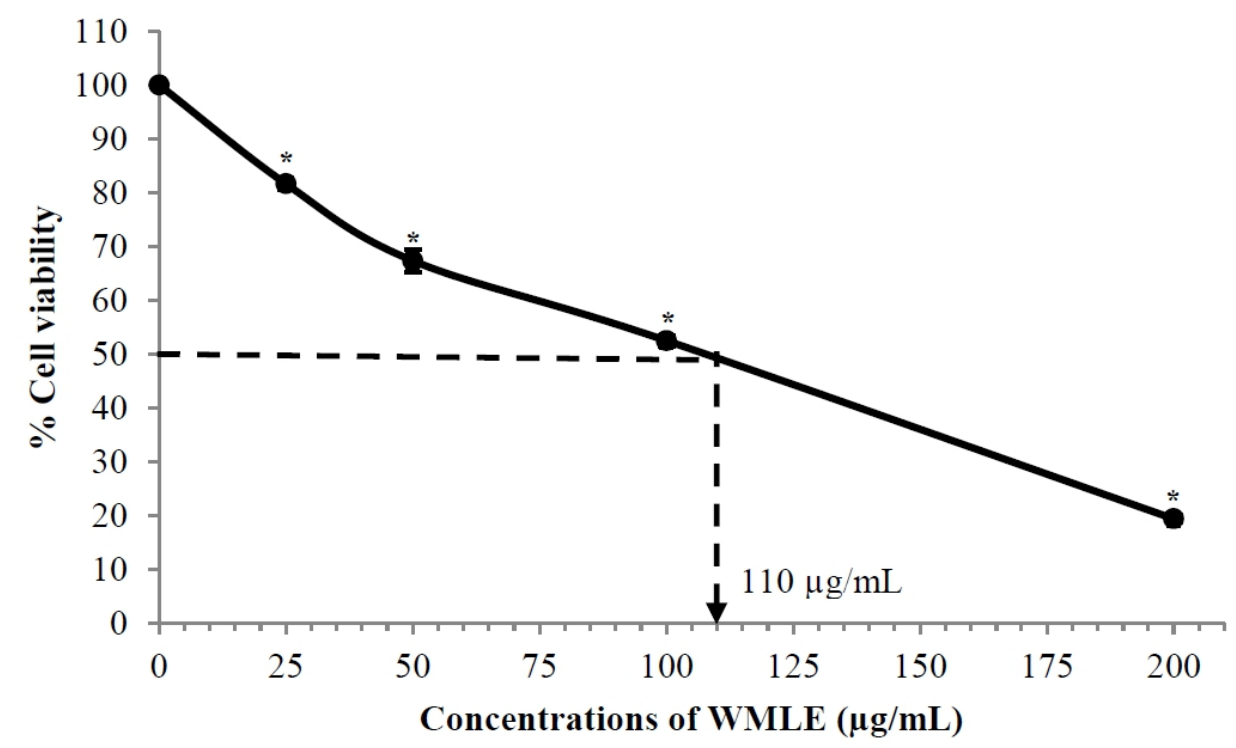

Figure 2 The percentage of cell viability of HepG2 cells against a various concentrations of WMLE (0 $200 \mu \mathrm{g} / \mathrm{mL}$ ) for $48 \mathrm{~h}$ of incubation. The data were obtained from 3-independent triplicate experiments and are shown as mean \pm SEM. $* P<0.05$ compared to non-treatment control.

\section{Effect of WMLE on intracellular ROS levels}

Oxidative stress response is modulated by an imbalance between production of reactive oxygen species (ROS) and capability of antioxidant enzyme to eliminate ROS. HepG2 cells are highly metabolic human liver cells which are produce large amounts of ROS. Implications of ROS regulation are highly 
http://wjst.wu.ac.th

significant for cancer treatment since ordinary antitumor drugs inhibit cancer cell proliferation through ability to accelerate cellular ROS production [23]. This ability, however, also affects damage to normal cells. Apparently, WMLE exhibited the antioxidant activity in the cultured HepG2 cells, demonstrated by dose-dependently reduction of cellular $\mathrm{H}_{2} \mathrm{O}_{2}$-derived-ROS levels (Figure 3). The WMLE at a concentration of $20 \mu \mathrm{g} / \mathrm{mL}$ significantly diminished the ROS levels. Results have shown that the natural antioxidants of white mugwort leaf extract strongly decrease the ROS levels in the HepG2 cell, thus may prevent or inhibit conditions that promote oxidative stress in the cell [24]. Yoshima Nakamura and colleagues [25] had previously demonstrated the inhibitory effects of the diacetylenes compounds isolated from the leaves of white mugwort on TPA-induced ROS formation in differentiated HL-60 cells. In this study, comparable influence on ROS levels between WMLE (Figure 3) and Trolox (Figure 4) was observed for HepG2 cells.

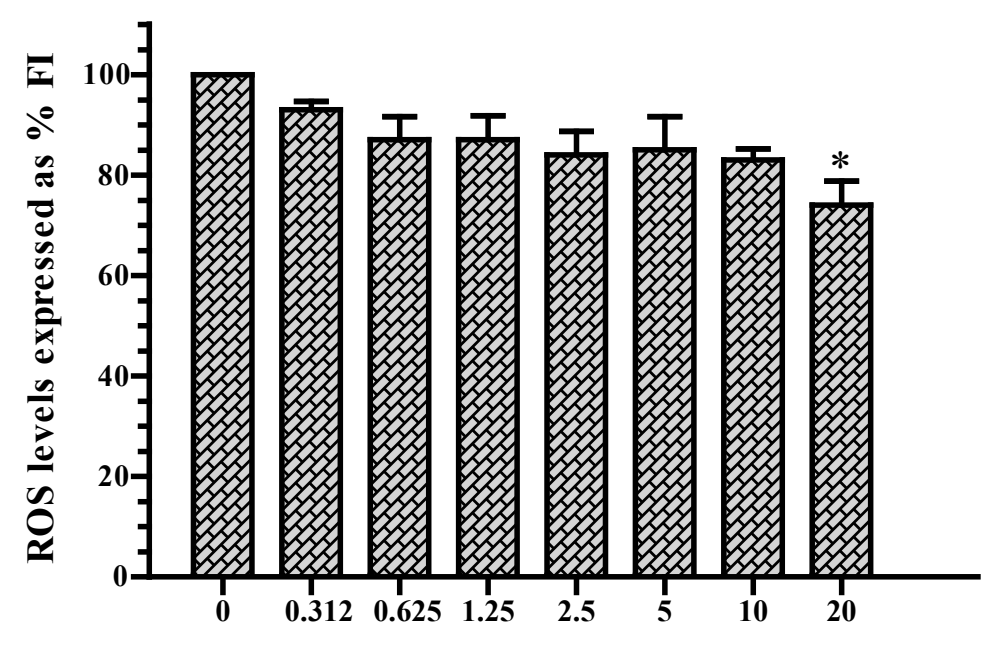

Concentrations of WMLE $(\mu \mathrm{g} / \mathrm{mL})$

Figure 3 The levels of ROS in 24 h-treated HepG2 cells with WMLE. The data were obtained from independent triplicate experiments and are shown as mean \pm SEM. ${ }^{*} P<0.05$ compared to non-treatment control. 


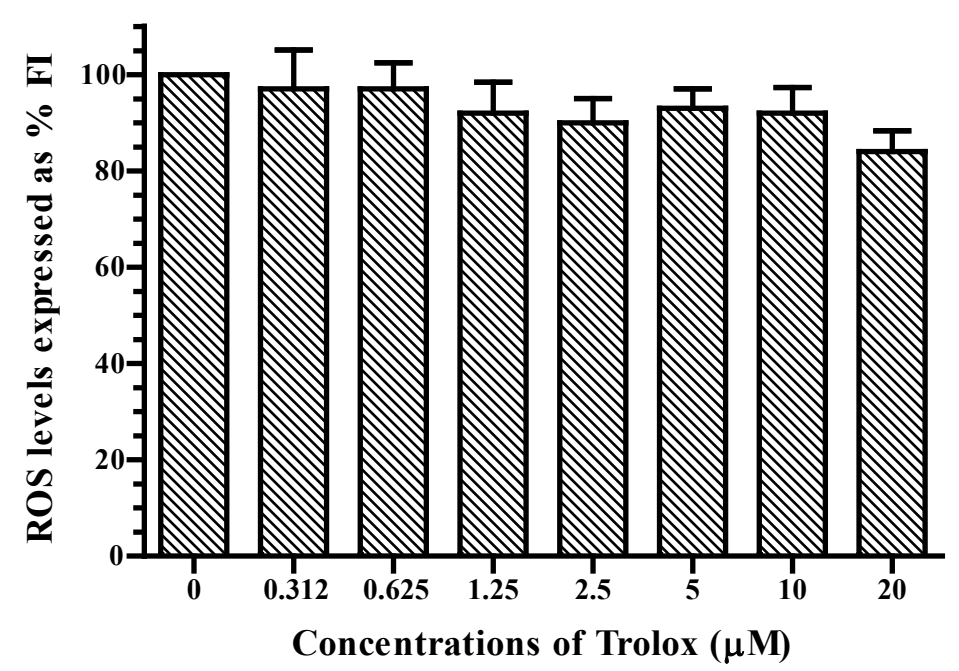

Figure 4 The levels of ROS in 24 h-treated HepG2 cells with Trolox. The data were obtained from independent triplicate experiments and are shown as mean $\pm \mathrm{SEM}$.

\section{Conclusions}

Concluded from results of this preliminary study, it is obvious that WMLE exhibits strong antioxidant activities while remain non-cytotoxic to HepG2 cell. Moreover, it was demonstrated that WMLE could reduce the levels of ROS in the cytosolic compartment of HepG2 cells. Nevertheless, further studies are needed to confirm and support the use of WMLE as a new alternative medicine for the remedy of liver cancer.

\section{Acknowledgements}

This work was supported by Chiang Mai University research grant, Chiang Mai, Thailand. The authors would like to thank Mr. Peeradet Poolsuk from Baanpakkhuntum, 182 Moo.1, Donkaew, Maerim, Chiang Mai 50180, Thailand, for supplying white mugwort leaves.

\section{References}

[1] MM Cowan. Plant products as antimicrobial agents. Clin. Microbiol. Rev. 1999; 12, 564-82.

[2] S Thevasundari and A Rajendran. Antibacterial potential and phytochemical analysis of Heterostemma tanjorense (WIGHT AND ARN). World J. Sci. Tech. 2011; 1, 39-45.

[3] VD Kancheva, OT Kasaikina. Bio-antioxidant: A chemical base of their antioxidant activity and beneficial effect on human health. Curr. Med. Chem. 2013; 20, 4784-805.

[4] C Brickell and D Kindersley. RHS A-Z Encyclopedia of Garden Plants. United Kingdom, 2008, p. 1136.

[5] YX Qian, JC Kang, BX Lei, L Wang and Y Huang. Screening and taxonomic identification of endophytic fungi with antitumor and antioxidant activities from Artemisia lactiflora. Zhongguo Zhong Yao Za Zhi 2014; 39, 438-41.

[6] A Siddiq and V Dembitsky. Acetylenic anticancer agents. Anticancer Agents Med. Chem. 2008; 8, 132-70.

[7] FD Lin, DW Luo, J Ye and MT Xiao. Chemical constituents of Artemisia lactiflora(II). Zhongguo Zhong Yao Za Zhi 2014; 39, 2531-5. 
http://wjst.wu.ac.th

[8] X Mei-tian, L Dang-wei, Z Ke, Y Jing, T Peng-Fei. A novel polyacetylene from the aerial parts of Artemisia lactiflora. Phytochem. Lett. 2014; 8, 52-4.

[9] M Liang, G Fan, T Chun-Ping, K Chang-Qiang, L Xi-Qiang, A Andreas and Y Yang. The absolute configuration determination of naturally occurring diacetylenic spiroacetal enol ethers from Artemisia lactiflora. Tetrahedron 2011; 67, 3533-9.

[10] T Starlin and V Gopalakrishnan. Enzymetic and non-enzymetic antioxidant properties of tylophorapauciflorawight and Arn an in vitro study. Asian J. Pharm. Clin. Res. 2013; 6, 68-71.

[11] MT Donato, L Tolosa and MJ Gomez-Lechon. Culture and functional characterization of human hepatoma HepG2 cells. Meth. Mol. Biol. 2015; 1250, 77-93.

[12] K Pangjit, L Udomsuk, S Upanan, A Pongjanta, N Chansiw and S Srichairatanakool. Iron-chelating and anti-hemolytic properties of ethanolic extract of lotus (Nelumbonucifera Gaertn) leaves. J. Med. Assoc. Thai 2016; 99, S58-S66.

[13] W Chen, Y Li, T Bao and V Gowd. Mulberry fruit extract affords protection against ethyl carbamate-induced cytotoxicity and oxidative stress. Oxid. Med. Cell Longev. 2017; 2017, 1594963.

[14] JS Cheng, CT Chou, YY Liu, WC Sun, P Shieh, DH Kuo, CC Kuo, CR Jan and WZ Liang. The effect of oleuropein from olive leaf (Olea europaea) extract on $\mathrm{Ca}(2)(+)$ homeostasis, cytotoxicity, cell cycle distribution and ROS signaling in HepG2 human hepatoma cells. Food Chem. Toxicol. 2016; 91, 151-66.

[15] ZZ Huang, C Chen, Z Zeng, H Yang, J Oh, L Chen and SC Lu. Mechanism and significance of increased glutathione level in human hepatocellular carcinoma and liver regeneration. Federat. Am. Soc. Exp. Biol. J. 2001; 15, 19-21.

[16] MM Soltan-Dallal, M Validi, M Douraghi, J Fallah-Mehrabadi and L Lormohammadi. Evaluation the cytotoxic effect of cytotoxin-producing Klebsiella oxytoca isolates on the HEp-2 cell line by MTT assay. Microb. Pathog. 2017; 113, 416-20.

[17] K Kulprachakarn, K Pangjit, C Phisalaphong, S Fucharoen, RC Hider and S Srichairatanakool. Combination treatments of 1-(N-acetyl-6-aminohexyl)-3-hydroxyl-2-methylpyridine-4-one (CM1) with deferiprone and desferrioxamine reduced labile iron pool and protected oxidative stress in ironloaded cutured hepatocytes. Vitam. Miner. 2013; 2, 1-8.

[18] K Perez-de-Arce, R Foncea and F Leighton. Reactive oxygen species mediates homocysteineinduced mitochondrial biogenesis in human endothelial cells: modulation by antioxidants. Biochem. Biophys. Res. Commun. 2005; 338, $1103-9$.

[19] J Amer, A Goldfarb and E Fibach. Flow cytometric measurement of reactive oxygen species production by normal and thalassaemic red blood cells. Eur. J. Haematol. 2003; 70, 84-90.

[20] PY Chao, SY Lin, KH Lin, YF Liu, JI Hsu, CM Yang and JY Lai. Antioxidant activity in extracts of 27 indigenous Taiwanese vegetables. Nutrients 2014; 6, 2115-30.

[21] S Dudonne, X Vitrac, P Coutiere, M Woillez and JM Merillon. Comparative study of antioxidant properties and total phenolic content of 30 plant extracts of industrial interest using DPPH, ABTS, FRAP, SOD, and ORAC assays. J. Agric. Food Chem. 2009; 57, 1768-74.

[22] M Xiao, J Ye, Y Huang and X Zhang. Response surface optimization for extraction of flavonoids from artemisia lactiflora wall. ex dc. and evaluation of antioxidant capacities in vitro. Asian $J$. Chem. 2014; 26, 2802-8.

[23] B Lin, X Tan, J Liang, S Wu, J Liu, Q Zhang and R Zhu. A reduction in reactive oxygen species contributes to dihydromyricetin-induced apoptosis in human hepatocellular carcinoma cells. Sci. Rep. 2014; 4, 1-7.

[24] MA Martin, S Ramos, R Mateos, ABG Serrano, M Izquierdo-Pulido, L Bravo and L Goya. Protection of human HepG2 cells against oxidative stress by Cocoa Phenolic extract. J. Agric. Food Chem. 2008; 56, 7765-72.

[25] Y Nakamura, Y Ohto, A Murakami, S Jiwajinda and H Ohigashi. Isolation and identification of acetylenic spiroketal enol ethers from Artemisia lactiflora as inhibitors of superoxide generation induced by a tumor promoter in differentiated HL-60 cells. J. Agric. Food Chem. 1998; 46, 5031-6. 